\title{
Aspectos estratégicos do modelo de gestão em incubadoras de empresas de base tecnológica
}

Deborah Moraes Zouain ${ }^{1}$

Aristeu Coelho da Silveira²

\section{Resumo}

Este artigo fundamenta-se na administração estratégica, focando as incubadoras de empresas de base tecnológica (IEBTs), - empreendimentos de apoio à criação e desenvolvimento de empresas dessa natureza. 0 texto ressalta a importância, verificada nos últimos anos, do movimento de incubadoras no Brasil, enfatizando a necessidade da adoção, pelas incubadoras, de modelos de gestão mais adequados à realidade nacional. Para tanto, foi feita uma pesquisa sobre 0 modelo dominante na gestão de incubadoras, além de uma comparação com o modelo conceitual descrito na literatura existente. Essa pesquisa teve caráter explicativo, e nela se recorreu a fontes bibliográficas, documentais e de campo. A incubadora da UFRJ e a da PUC/RJ constituem a amostra que foi definida pelo critério da acessibilidade. 0 resultado evidencia como modelos de gestão mais adequados propiciam melhores condições para o sucesso desse tipo de empreendimento.

Palavras-chave: administração estratégica; gestão de incubadoras; empresas de base tecnológica; empreendedorismo; incubadoras da PUC/RJ e da UFRJ.

\begin{abstract}
The study is based on strategic administration, focusing on incubators of technology-based companies, namely support undertakings for the spawning and development of such kind of companies. It stresses the importance over the past few years of the movement of incubators in Brazil and underscores the need, on the part of incubators, to adopt management models that are more relevant to the Brazilian reality. For this purpose, research was conducted into the dominant model in incubator management, as well as a comparison with the conceptual model described in existing literature. The research was of an explanatory nature making use of bibliographical, documentary and field sources. The criteria of accessibility and existing structure of two incubators (UFRJ and PUC/RJ) determined the sample. The results show how more adequate models provide better conditions for the success of this type of undertaking
\end{abstract}

Key words: strategic administration; incubator management; technology-based companies; entrepreneurship; PUC/RJ and UFRJ incubators.

\footnotetext{
Doutora em Engenharia de Produção pela COPPE/UFRJ. Vice- Diretora da EBAPE. Endereço: Praia de Botafogo, 190 - sala 538 - Botafogo - Rio de Janeiro - RJ 22250-900. E-mail: deborah@ fgv.br.

${ }^{2}$ Mestre em Administração pela EBAPE/FGV. Praia de Botafogo, 190- Sala 538 - Botafogo- RJ- 2250900. E-mail: aristeu@ aristeusilveira.com.br.
}

Artigo recebido em abril de 2006 e aceito para publicação em junho de 2006. 


\section{Introdução}

Compreender a importância do uso da tecnologia para o desenvolvimento humano, como conjunto de conhecimentos desenvolvidos para resolver problemas do homem, tornou-se fundamental. A ciência e a tecnologia são, hoje, os principais fatores que agregam valor à produção, e conseqüentemente são agentes catalisadores determinantes para o desenvolvimento econômico e o bem-estar social de uma região. A política tecnológica de uma nação afeta diretamente incontáveis setores, como o de saúde, educação, transportes, comunicação e, particularmente, sua produtividade e competitividade. A nação que não domina ou não participa dos processos de inovação tecnológica está destinada à estagnação e à dependência. Investir no trinômio ciência-tecnologia-inovação é essencial para a sobrevivência das empresas e para o próprio futuro do país. Competitividade e domínio tecnológico tornaram-se a essência de todo o progresso previsível para as próximas décadas.

Dessa perspectiva, as universidades são chamadas a desempenhar um papel estratégico no desenvolvimento do setor produtivo, o que lhes impõe a busca de conteúdos e abordagens curriculares que atendam à demanda por novos conhecimentos e tecnologias, assim como ao desenvolvimento de iniciativas que estimulem a transferência tecnológica dos centros de pesquisa para o mercado.

Atualmente, muitas universidades brasileiras têm buscado fomentar o empreendedorismo de base tecnológica através de programas específicos e de incubadoras de empresas. Estimulam seu desenvolvimento, oferecendo recursos e instalações apropriados, sem contar o apoio institucional de centros de pesquisa, do Serviço de Apoio às Pequenas e Médias Empresas (Sebrae), de prefeituras municipais, da Financiadora de Estudos e Projetos (Finep) e do Instituto Nacional de Propriedade Industrial (INPI), dentre outros.

O movimento de incubadoras brasileiro cresceu sobretudo na década de 1990, e vem contando, para sua disseminação e fortalecimento, com as ações da Associação Nacional de Entidades Promotoras de Empreendimentos de Tecnologias Avançadas (Anprotec) que, junto com seus parceiros, desenvolve iniciativas voltadas para o planejamento de incubadoras, a capacitação dos gerentes e também para a criação de núcleos de referência, procurando estabelecer modelos replicáveis dentro do movimento. É inegável o potencial impacto positivo dos programas de incubação no Brasil, tanto no desenvolvimento das empresas que participam de programas dessa natureza, quanto nas economias locais e regionais. No entanto, segundo Aranha (2002), nos últimos anos o movimento de incubadoras tem sido questionado acerca de sua eficiência no Brasil e no mundo. No Brasil isso se deve, em grande parte, à ausência de modelos de gestão que possibilitem uma melhor avaliação do desempenho das incubadoras. Para Caulliraux (2001), a falta de modelos de gestão mais ajustados à realidade das incubadoras brasileiras, bem como de critérios estruturados de avaliação de desempenho, também implica uma questão que é freqüentemente discutida em fóruns sobre o tema - os problemas que as agências de fomento e os patrocinadores não-governamentais têm para avaliar a eficiência do apoio financeiro voltado para as incubadoras de empresas, o que até pode inibir o incentivo a esse tipo de programa.

Segundo Aranha (2002), os programas de incubação de empresas nasceram nos EUA, decorrentes da expansão de três diferentes movimentos que se desenvolveram simultaneamente - o de condomínios de empresas, o de programas de empreendedorismo e o de investimentos em novas empresas de tecnologia. O embrião dessa idéia - visto como o start up para pequenos empreendedores - sofreu algumas transformações desde sua origem, a partir de um processo gradual de agregação de valores e experiências até chegar à concepção atual de incubadora. Hoje, os programas de incubação de empresas abarcam seus três movimentos originais. São processos dinâmicos de formação de empreendedores e empreendimentos, alimentados por investimentos de diversas naturezas, respaldados nos ativos intelectuais e tecnológicos de centros de formação e pesquisa.

De acordo com Baêta (1999), as incubadoras de empresas de base tecnológica constituem espaços privilegiados para empresas situadas nessa categoria. As IEBTs oferecem espaço e serviços subsidiados que ajudam a empresariar e a desenvolver produtos e processos de alto conteúdo científico e tecnológico nas áreas de informática, biotecnologia, química fina, de novos materiais e de mecânica de precisão, dentre outros. A empresa de base tecnológica é aquela que fundamenta sua atividade produtiva no desenvolvimento de novos 
produtos/serviços ou processos, alicerçados na aplicação sistemática de conhecimento científico-tecnológico e na utilização de técnicas consideradas avançadas ou pioneiras. Nessas empresas, a tecnologia é o diferencial de competitividade; isto é, a inovação tecnológica é a razão da maior parte dos custos da empresa, além do fato de que é em tecnologia que a maioria do pessoal da empresa trabalha.

O sucesso das incubadoras é, em grande parte, definido pelo sucesso das empresas residentes. O que é percebido pelo cliente final - representantes da sociedade que apóiam tais empreendimentos - é o sucesso das empresas residentes, fato que decorre diretamente do processo de incubação. Segundo Baêta (1999), dentre outros motivos, a maior parte do fracasso das empresas deve-se à descontinuidade do processo de inovação, ao rompimento da relação com a incubadora e ao afastamento das instituições de pesquisa. $\mathrm{Na}$ análise organizacional das IEBTs, as estratégias gerenciais indicam uma nova forma organizadora para a transferência de tecnologia. O conceito de gerência está relacionado com a atividade exercida pelo agente gestor, o qual atua como elo entre os vários parceiros da incubadora e as empresas residentes.

A área de tecnologia avançada nos conduz a uma estrutura ímpar que promove a gestão de parcerias, combinando a gerência da incubadora com a gestão da inovação. A gestão da inovação se caracteriza por empregar conhecimentos da engenharia e das ciências, de modo geral, e também da administração, para planejar, desenvolver e implantar competências tecnológicas capazes de formular e atingir objetivos estratégicos. Desse modo, gerenciar uma IEBT requer habilidade para lidar com situações complexas e criar estratégias capazes de catalisar esforços de diferentes agentes.

\section{Modelo de gestão para incubadoras}

A questão-chave para se definir um modelo de gestão é o entendimento sobre as características do objeto de estudo, seus principais processos, suas competências centrais, suas relações com os agentes externos que influenciam seu desempenho e sua estratégia de atuação. Nesse caso, a premissa básica para a montagem de um modelo para incubadoras de empresas seria a existência de fundamentos estratégicos bem definidos. Logo, deveriam ser estabelecidos os aspectos que definem o papel da incubadora na comunidade e na sociedade, para que pudesse ser desenvolvido um modelo capaz de garantir que seu objetivo principal - transformar idéias em empresas auto-sustentáveis - fosse alcançado. As organizações sem fins lucrativos (categoria na qual podemos enquadrar os programas de incubação, no caso brasileiro) são particularmente propensas à ambigüidade de controle e de critérios de sucesso, devido à existência de muitos stakeholders - que adotam múltiplos trade-offs no processo decisório - (BEARSE, 1993). Além disso, segundo Caulliraux (2001), produzem bens coletivos ou difíceis de avaliar, o que confere importância ainda maior ao estabelecimento de uma missão e à manutenção da consistência com a mesma para realizar avaliações.

\section{Os processos-chave nas incubadoras de empresas}

Segundo Caulliraux (2001), o macroprocesso principal das incubadoras de empresas é o de residência, ou seja, a transformação de candidatos em empresas, o que conseqüentemente é o principal objetivo dos programas de incubação. A transformação de candidatos em empresas é, portanto, seu principal produto. Além disso, o referido autor assinala que as atividades internas das incubadoras estão voltadas para o provimento de estrutura, ambiente e serviços, de forma que as empresas residentes possam se desenvolver da melhor maneira possível, aptas a sobreviverem num mercado competitivo. De maneira geral, as incubadoras buscam aumentar a eficiência de seu processo principal através:

- da melhoria da qualidade dos candidatos;

- do aumento da eficiência do período de residência e

- pelo aumento das chances de sobrevivência das empresas graduadas.

Dessa forma, os processos das incubadoras de empresas devem ser definidos para que se alcance maior eficiência na geração de seu produto principal. 
Figura 1

Macroprocesso principal dos programas de incubação

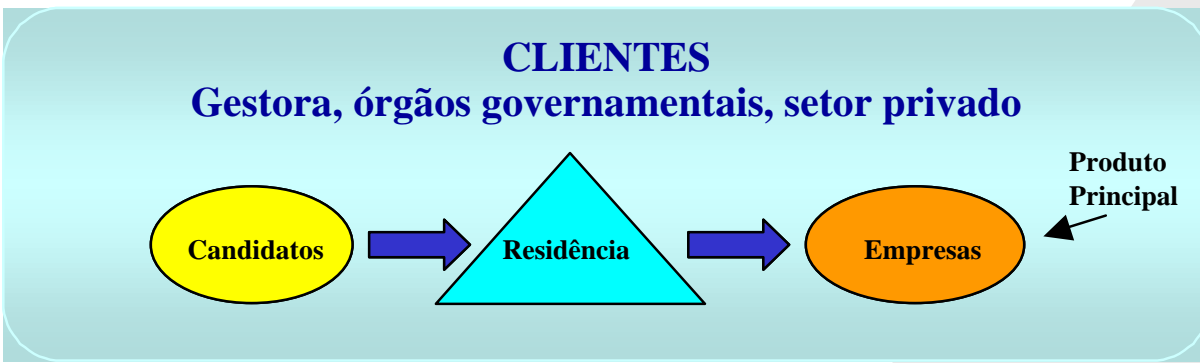

Fonte: Caulliraux (2001, p.11).

\section{Processos principais:}

- processo de pré-incubação - reúne todas as iniciativas desenvolvidas que têm por objetivo melhorar a qualidade e aumentar a quantidade de candidatos aos programas de incubação;

- seleção de candidatos ao programa de incubação - visa garantir a qualidade e adequar os proponentes ao ambiente da incubadora;

- assistência e acompanhamento de empresas residentes - reúne todas as atividades de acompanhamento do progresso e da situação das empresas residentes e a assessoria, para a melhora e crescimento das empresas;

- graduação - são atividades realizadas para que a empresa possa deixar a incubadora e se instalar no mercado;

- acompanhamento das graduadas - é a análise periódica das empresas já graduadas pela incubadora e de seu impacto econômico, social e tecnológico;

- captação - engloba desde a elaboração de projetos para captar recursos de instituições de fomento e órgãos financiadores - para a melhoria e o crescimento dos programas de incubação - até a execução e o acompanhamento desses projetos.

Figura 2

Processos principais das incubadoras de empresas

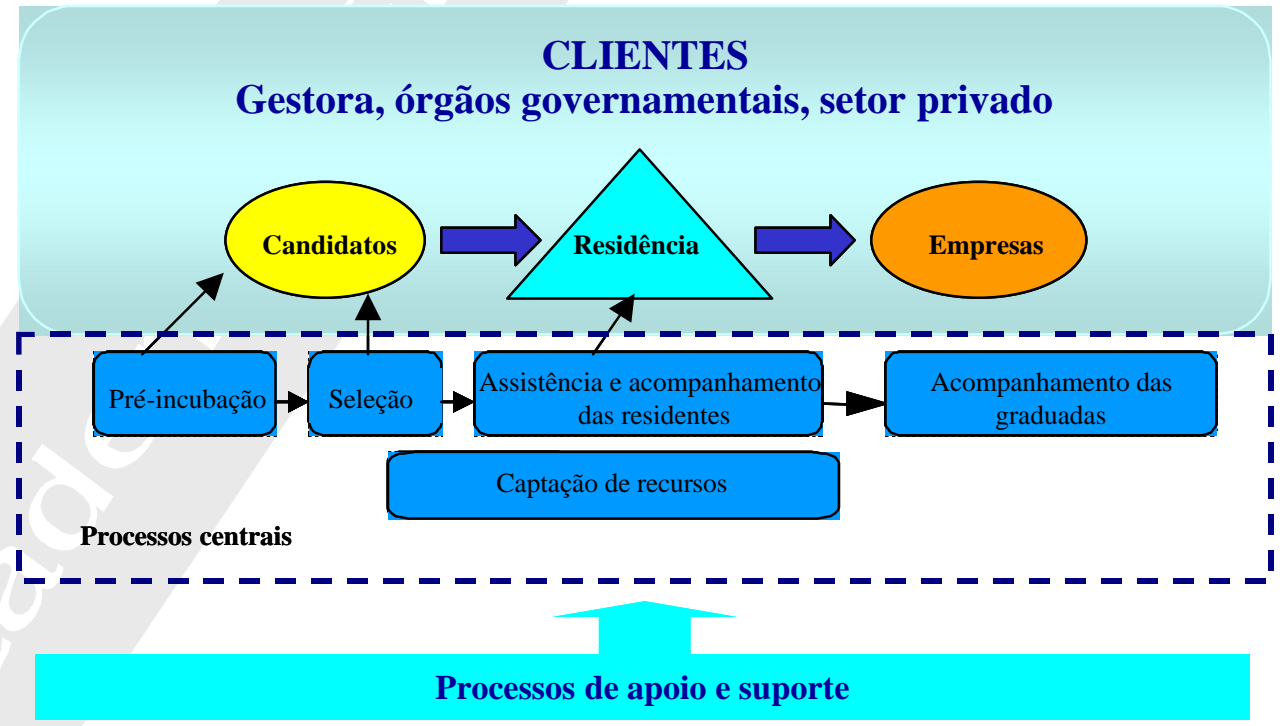

Fonte: Caulliraux (2001, p.11). 
A segunda categoria de processos é relativa às atividades de apoio e suporte; ou seja, são aqueles processos que não influenciam diretamente o processo principal das incubadoras, mas dão sustentação a toda a estrutura necessária à sua execução. De modo geral, essa categoria é separada em dois grupos. O primeiro engloba todas as atividades rotineiras; o segundo, aquelas atividades específicas (Caulliraux, 2001). Neste caso, os processos de apoio e suporte englobam as seguintes atividades: contabilidade e finanças, marketing, planejamento, recursos humanos, compras, gerenciamento de ativos, serviços gerais, assessoria jurídica, dentre outras.

\section{Figura 3}

Processos de apoio às incubadoras
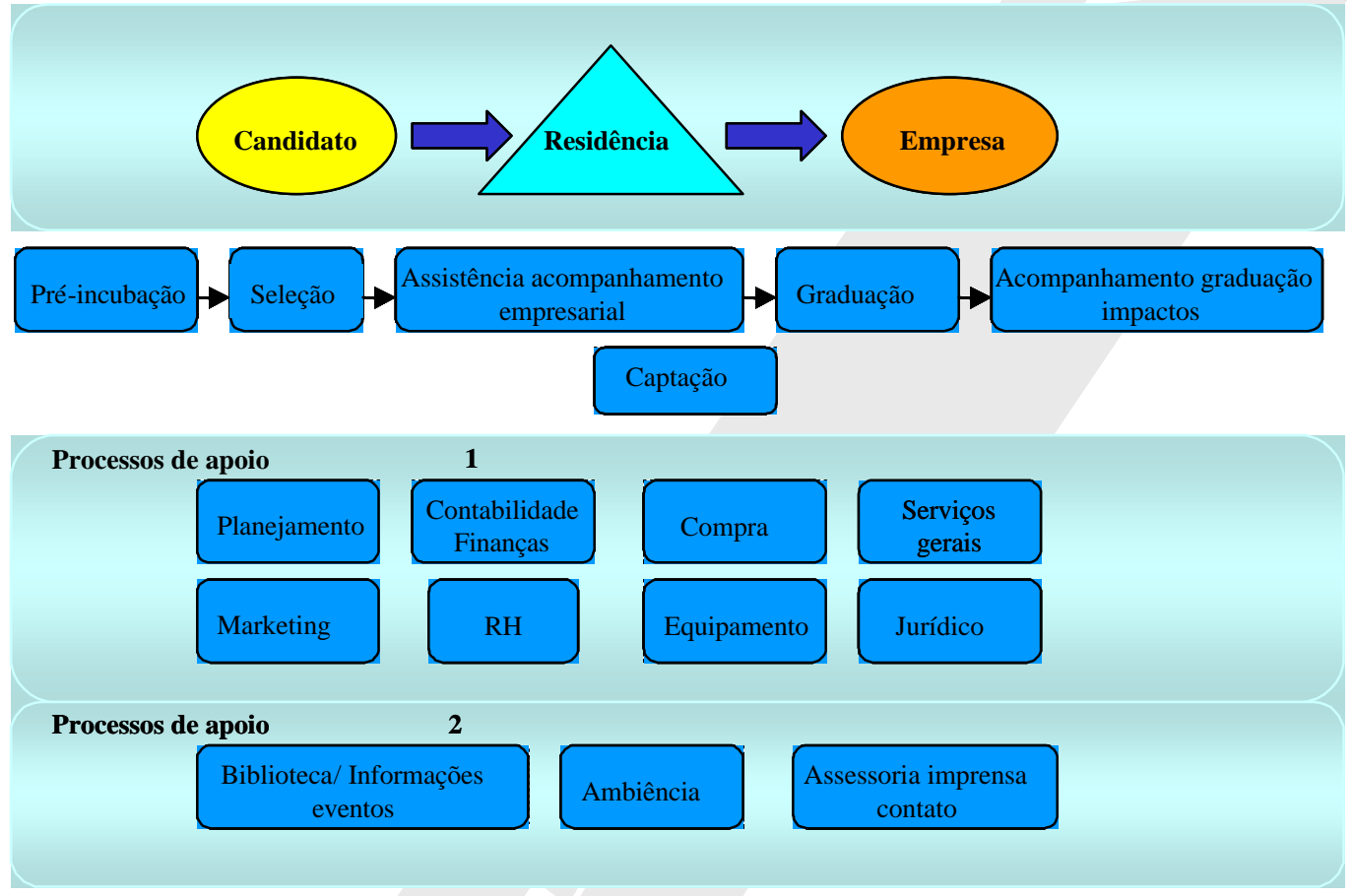

Fonte: Relatório de Incubadoras/RJ, p.31- 2000.

\section{Aspectos estratégicos em incubadoras}

Segundo Aranha (2002), a grande maioria das incubadoras de empresas está vinculada a uma instituição mantenedora. Geralmente, em sua relação com a mantenedora, as incubadoras funcionam como programas desenvolvidos por uma unidade da instituição - um departamento, um núcleo de pesquisa ou por mais de uma unidade - emergindo da interação e do trabalho cooperativo entre diferentes setores. $\mathrm{O}$ vínculo com uma instituição mantenedora leva a incubadora a fazer parte de uma estrutura maior, a estar inserida numa organização (de modo geral, mais complexa) e a aderir à sua dinâmica. A incubadora deverá integrar-se à filosofia e aos objetivos estratégicos definidos pela instituição. Assim, deverá haver um alinhamento estratégico entre a mantenedora e a incubadora.

As incubadoras contam também com o apoio de parceiros externos que subsidiam (através da oferta de recursos) a estrutura de suporte técnico-gerencial e ações para o desenvolvimento de negócios destinados aos empreendedores e às empresas. A continuidade desse apoio depende da apresentação dos resultados esperados e das expectativas dos parceiros em relação à incubadora. $\mathrm{O}$ processo de negócio de uma incubadora tem como insumo uma idéia ou um candidato que, após o período de permanência nesta, deve se transformar numa empresa de sucesso. $\mathrm{O}(\mathrm{s})$ fornecedor(es) do insumo pode $(\mathrm{m})$ variar segundo a natureza e os objetivos da instituição mantenedora, e também conforme o público-alvo da própria incubadora. 
Em incubadoras de base tecnológica, as fontes de fornecimento são normalmente universidades e/ou centros de pesquisa. $\mathrm{O}$ insumo pode chegar à incubadora em diversos estágios de desenvolvimento - pode ser uma idéia, uma pesquisa aplicada, o protótipo de um produto ou um empreendedor com grande potencial.

Para Aranha (2002), a transformação de candidatos ou idéias em empresas de sucesso - durante o período de incubação e após as empresas se graduarem - acontece através do acompanhamento do processo de amadurecimento do negócio e da indução ou intervenção em fatores críticos de sucesso em diferentes estágios da vida das empresas. Isso se dá por meio da oferta de serviços e consultorias técnicas e estratégicas e da promoção de um ambiente favorável à formação contínua do empreendedor e à geração de inovação. Essas ações da incubadora são possíveis graças à interação e convergência de competências e conhecimentos (oriundos de diversas áreas da ciência) e contam com o apoio da mantenedora e dos parceiros.

Um modelo de gestão para incubadoras deve considerar as peculiaridades dessas organizações, levando-se em conta as diversas instâncias decisórias implícitas no vínculo com uma instituição mantenedora e na existência de parceiros. O planejamento da entidade gestora é premissa para a execução no nível da entidade executora, estendendo-se para as empresas incubadas e graduadas. $\mathrm{O}$ modelo de gestão de incubadoras de empresas precisa incorporar a interação dos vários agentes do programa de incubação (gestora, parceiros, incubadora e empresas) com o ambiente externo (micro e macro) e sua dinâmica. Um modelo de gestão para incubadoras deve, além de considerar as várias instâncias decisórias e os aspectos interativo e dinâmico do processo de incubação, ser articulado através de módulos que se comunicam e estar amparado numa estrutura organizacional flexível e que permita à organização se adaptar e inovar.

\section{Gestão estratégica de programas de incubação}

\section{Visão geral do modelo de gestão da entidade gestora}

Em seu estudo, Aranha (2002) apresenta os elementos conceituais do planejamento estratégico da entidade gestora de um programa de incubação, (baseando-se nos parâmetros de atuação da mesma) que definirão as diretrizes de atuação da incubadora:

- análise dos stakeholders;

- valores e crenças;

- missão;

- visão;

- estrutura da organização;

- objetivos estratégicos e planos de metas;

- estratégia de posicionamento (diretrizes) para a incubadora;

- fatores críticos de sucesso; e

- os indicadores de desempenho.

Em programas de incubação, os projetos e programas garantem um foco específico nas estratégias que exigem ações fora do cotidiano. Estratégicos, táticos ou operacionais, os projetos são classificados de acordo com o grau de impacto que os seus resultados trarão para a organização. Projetos estratégicos impactam diretamente o futuro do programa, criam uma nova realidade e desenvolvem novos padrões de desempenho, alinhados com a visão de futuro. Projetos táticos impactam as etapas intermediárias no caminho desse futuro, podendo ser vistos como sustentáculos do desenvolvimento, enquanto os projetos operacionais tratam das questões mais imediatas.

Descendo na hierarquia do planejamento, inicia-se com os objetivos e as estratégias idealizadas para levar o programa de incubação ao seu futuro (junto com alguns projetos considerados estratégicos), passando pelos 
projetos e ações táticas que deverão ser desenvolvidos nos anos seguintes, chegando-se até os projetos e as iniciativas de curto prazo, necessárias para a construção diária desse futuro.

Na etapa tática do planejamento, também denominada de planos táticos, são explicitadas as metas, os recursos e os prazos a elas associados, dentro de um horizonte de médio prazo. Na etapa operacional, são definidas as ações específicas que devem ser desenvolvidas, geralmente, no prazo de um ano. Para o acompanhamento desse processo de implementação das estratégias, é preciso desenvolver um sistema de indicadores de desempenho que consiga abranger três níveis:

- o estratégico - através de indicadores macro, associados aos objetivos estratégicos;

- o tático - através de indicadores de desempenho associados às metas;

- o operacional - através de indicadores de desempenho associados às atividades operacionais de curto prazo.

Os indicadores de desempenho têm sido geralmente mais utilizados nas organizações para o acompanhamento financeiro e para o controle de produção. Outros, mais recentes, têm procurado expressar o desempenho, de acordo com enfoques mais abrangentes, como as opiniões dos clientes sobre o serviço ou produto etc. Especificar adequadamente um indicador para o processo de avaliação do progresso de implementação das estratégias é uma atividade vital nesse processo. O sistema de indicadores da entidade gestora de um programa de incubação deve medir o grau de adesão aos fundamentos estratégicos da instituição gestora. No módulo de planejamento estratégico, são identificados apenas os indicadores da organização, para que sua medição seja realizada no módulo de controle. Adiante, são apresentados alguns indicadores de desempenho sugeridos pelo Comitê Gestor do Programa Nacional de Apoio às Incubadoras de Empresas.

- indicadores de pré-incubação - número total de projetos em pré-incubação/número total de empresas incubadas, número de projetos incubados resultantes da pré-incubação/número de projetos em préincubação, número de projetos em pré-incubação com pedidos de registro no INPI/número total de projetos em pré-incubação, número de projetos em pré-incubação que se tornaram empresas sem passar por incubadoras/número total de projetos em pré-incubação, número de alunos envolvidos em projetos na fase de pré-incubação/número total de alunos matriculados em programas de empreendedorismo e o número de projetos em pré-incubação originados de pesquisa desenvolvida em centros tecnológicos/número total de projetos em pré-incubação;

- indicadores de incubação - número de projetos selecionados para incubação/número total de projetos candidatos à incubação, total de faturamento nos últimos 12 meses das empresas residentes/número total de empresas residentes, total de faturamento nos últimos 12 meses das empresas residentes/número total de colaboradores das empresas residentes, número de rescisões contratuais/número total de empresas graduadas, número de módulos ocupados/número total de módulos disponíveis, número de empresas graduadas/número de empresas incubadas, numero total de produtos (serviços) gerados pelas empresas incubadas/número de empresas incubadas, tempo de incubação (meses) das empresas graduadas/número total de empresas graduadas, total de custos operacionais/total de receitas próprias, total de faturamento nos últimos 12 meses das empresas residentes/total de faturamento das empresas residentes no período anterior, número de empresas incubadas com pedidos de registros (patentes) no INPI./número total de empresas incubadas, número de empresas certificadas (ISO, PNQ etc.)/número de empresas incubadas e o número total de empresas graduadas estabelecidas no mercado/número total de empresas graduadas;

- indicadores de pós-incubação - número de empresas graduadas com vínculo formal com instituições de pesquisa/número total de empresas graduadas, número de empresas graduadas instaladas em parques tecnológicos/número total de empresas graduadas, total de faturamento nos últimos 12 meses das empresas graduadas/número total de empresas graduadas e o total de faturamento nos últimos 12 meses das empresas graduadas/número total de colaboradores das empresas graduadas; 


\section{Planejamento da incubadora - modelo conceitual}

Em seu estudo, Aranha (2002) defende que o módulo de planejamento da incubadora deve representar a definição dos objetivos, do plano de metas e das estratégias operacionais vinculados ao processo de negócio da entidade executora. Como a incubadora se insere em uma estrutura maior, fazendo esta parte de unidades da entidade gestora, seu processo de negócio deverá estar compreendido nos processos da gestora. $\mathrm{O}$ autor mencionado sugere que se utilize essa sequiência de seis passos:

- passo 1 - alinhar percepções quanto ao futuro;

- passo 2 - mapear os processos;

- passo 3 - definir missão e visão;

- passo 4-definir os objetivos e metas;

- passo 5 - formular a estratégia da entidade executora, e

- passo 6 - definir indicadores de desempenho operacionais.

Os indicadores da entidade executora são aqueles que irão avaliar o desempenho de seu principal processo de negócio e os processos de apoio que dão sustentação ao negócio da incubadora. Caulliraux (2001) sugere uma lista de indicadores preliminares que devem ser adequados à estratégia e ao modelo de gestão particular de cada incubadora:

- indicadores dos processos de pré-incubação - número de alunos matriculados nas disciplinas de empreendedorismo, número de atendimentos a interessados, número de retiradas do edital/número de planos confeccionados e o número de projetos estimulados/realizados;

- indicadores do processo de seleção - número de candidatos/número de selecionados, planos de negócio apresentados/selecionados e número de alunos na disciplina de empreendedorismo/número de propostas de alunos da disciplina;

- indicadores do período de residência - taxa de inadimplência, taxa de ocupação, total de faturamento das empresas residentes, tempo médio de residência, taxas de mortalidade e de sucesso, número de funcionários empregados, quantidade de empregos qualificados gerados, número de produtos gerados, salários pagos, número de estágios, imposto gerado, índice dos custos operacionais cobertos pelas empresas, taxa de crescimento das empresas, satisfação dos clientes (empresas), número de patentes geradas e os investimentos de capital de risco nas empresas;

- indicadores das empresas graduadas - total de faturamento, taxas de mortalidade e de sucesso, número de funcionários empregados, número de empregos qualificados, número de produtos, investimentos/número de empresas, número de empresas geradas, impacto de modernização das empresas, potencial de importação das empresas e a inovação classe mundial;

- indicadores do processo de captação de recursos - número de projetos preparados/aprovados;

- indicadores da gestão da incubadora - índice de auto-sustentação, o custo operacional incubadora/empregos gerados, empresas geradas etc., a transferência de tecnologia (contratos com a universidade, spin-offs), a satisfação da equipe da incubadora, a qualificação da equipe da incubadora, além do percentual dos custos totais cobertos pela incubadora.

\section{Implementação e controle estratégico em incubadoras}

Em seu estudo, Caulliraux (2001) apresenta um balanced scorecard para incubadoras. Entretanto, cada incubadora é desenvolvida para alcançar objetivos específicos que dependem, entre outras coisas, da instituição a qual está vinculada e da região onde está estabelecida. Percebe-se também que a estratégia de cada incubadora pode ser influenciada pelo estágio de desenvolvimento do programa ou, mesmo, pelo propósito para o qual foi criada. Para desenvolvermos um modelo de avaliação, é necessário analisar e documentar as várias 
inter-relações e influências que afetam a maneira como a incubadora alcançará seus próprios objetivos e o dos stakeholders.

Para a elaboração da estrutura de indicadores de desempenho devem ser adotadas algumas premissas que formam a base para o desenvolvimento desse balanced scorecard:

- o sucesso das incubadoras é, em grande parte, definido pelo sucesso das empresas residentes;

- o processo principal de uma incubadora é a transformação de candidatos em empresas, sendo esta portanto, seu principal produto;

- os clientes foram definidos como a entidade gestora e os órgãos de fomento;

- as incubadoras de empresas foram criadas, em todas as partes do mundo, para atenderem a abrangentes metas de desenvolvimento social, econômico e tecnológico, defendendo os interesses de toda a sociedade.

Essa estrutura de indicadores deve ser direcionada de acordo com a visão/estratégia de cada incubadora. Processos e relações de causa e efeito devem ser focalizados, objetivando o alcance de metas particulares a cada incubadora. $\mathrm{O}$ sucesso da empresa residente depende, em grande parte, da incubadora e vice-versa; por isso é necessária a construção e a análise de duas estruturas. Atividades realizadas pela incubadora impactam outras da empresa incubada, assim como alguns resultados obtidos pelas residentes atingem processos da incubadora, daí a grande ligação entre as duas estruturas. De maneira geral, essas estruturas simplificadas apresentam relações de dependência entre atividades e resultados. Muitas dessas relações de causa e efeito são mensuráveis. Quanto a outras, não existe essa possibilidade. Alguns processos apresentam, inclusive, relações contraditórias, pois, por exemplo, melhoram um indicador de processos internos, mas aumentam as despesas , de uma perspectiva financeira.

\section{Casos de programas de incubação analisados}

Essa seção do artigo resume o resultado da pesquisa realizada sobre as incubadoras tecnológicas da Pontifícia Universidade Católica do Rio de Janeiro (PUC/RJ) e da Universidade Federal do Rio de Janeiro (UFRJ), que constituem a amostra selecionada.

\section{Incubadora de base tecnológica do Instituto Gênesis (PUC/RJ) $)^{3}$}

O Instituto Gênesis para Inovação e Ação Empreendedora surgiu como forma de consolidar as estruturas e ações destinadas ao desenvolvimento e administração das atividades do Programa de Formação de Empreendedores da PUC/RJ. O instituto é uma unidade complementar da universidade, vinculada à vicereitoria para assuntos acadêmicos. A missão do instituto é transferir conhecimento da universidade para a sociedade e contribuir para a melhoria da qualidade de vida da região onde se insere, através da formação de empreendedores e da geração de empreendimentos inovadores de sucesso.

\section{A incubadora tecnológica Gênesis}

A incubadora tecnológica Gênesis foi inaugurada em julho de 1997 como uma das ações promovidas pelo Instituto Gênesis para difundir a cultura empreendedora. Para tanto, o instituto contou com o apoio de instituições como Citibank, Finep, Fundação Padre Leonel Franca, Rede de Tecnologia do Rio de Janeiro, prefeitura do Rio de Janeiro e governo do estado do Rio de Janeiro - através da Faperj e da Cehab, que cedeu o terreno para as instalações do prédio.

\footnotetext{
${ }^{3}$ Todos os dados foram obtidos através de material fornecido pela incubadora, do sítio www.puc-rio.br e do estudo de Caulliraux (2001).
} 


\section{Fundamentos estratégicos da incubadora}

- missão - "gerar empreendimentos auto-sustentáveis dando suporte no desenvolvimento de empresas emergentes com base tecnológica."

- visão - "ser um canal de prestação de serviços da universidade para a sociedade, gerando empresas, conhecimento, trabalho e renda."

\section{Objetivos estratégicos:}

- tornar-se membro de um pólo de tecnologia na região, envolvendo instituições que promovam o desenvolvimento nessa área, intercambiando universidade/empresas/governo;

- difundir a cultura empreendedora no ambiente da PUC/RJ e no país;

- promover a interação entre empresas residentes e a universidade;

- atender à necessidade da região onde a incubadora está inserida.

A seleção das empresas para a incubadora tecnológica é feita por meio de edital e o tempo médio de incubação é de dois anos. O processo de seleção tem a seguinte metodologia:

- orientação;

- entrega dos planos de negócios;

- análise dos planos de negócios;

- entrevista dos candidatos pré-selecionados;

- reunião dos analistas;

- resultado da primeira fase do edital;

- apresentação prévia;

- apresentação para o consórcio;

- resultado da seleção final;

- assinatura do convênio de desenvolvimento empresarial;

- reunião de ambientação; e

- entrada na incubadora.

As empresas incubadas têm acesso a recursos como sala para instalação da equipe, auditório, sala de reuniões, acesso à Internet e à rede interna do prédio, além de apoio e consultoria das unidades operacionais Gênesis. As regras de concessão desses recursos são estabelecidas no convênio de desenvolvimento empresarial e em reuniões periódicas entre a gerência da incubadora e as empresas.

\section{A gestão da incubadora:}

- função marketing - o marketing é responsável por atender às demandas e expectativas da comunidade, da PUC/RJ (instituição mantenedora), das instituições parceiras, do conselho consultivo, dos investidores, das empresas graduadas e residentes, enfim, do sistema de relações Gênesis;

- assessoria de novos negócios - apoiar, dar assistência e acompanhar as demandas e expectativas dos alunos, candidatos e empresas da incubadora, organizar o processo de seleção das empresas, auxiliar na captação de recursos e apoiar juridicamente as empresas e a incubadora;

- apoio jurídico - orientar e dar informações no campo do direito para a incubadora e para as empresas residentes; 
- assessoria de comunicação - funcionar como um canal de diálogo entre a incubadora e o público. Ela atua no sentido de promover a imagem institucional da incubadora e das empresas residentes. Também é compreendida como uma responsabilidade social, um meio de prestar contas sobre atividades que produzem efeitos na vida em sociedade;

- gestão financeira - a filosofia financeira da incubadora está baseada em alguns pilares, como a busca constante da auto-suficiência operacional;

- assessoria de projetos - captar recursos para a incubadora;

- assessoria financeira - atingir a auto-suficiência operacional na gestão financeira com planejamento, orçamento, política de controle de custos e custeio; acompanhamento individual e constante das empresas incubadas, melhorias nas relações com as parcerias incubadora/PUC, incubadora/Fundação Padre Leonel Franca (FPLF), incubadora/empresas, incubadora/parceiros externos e incubadora/projetos;

- assessoria administrativa - apoiar as empresas residentes com serviços compartilhados do condomínio para o bom funcionamento da incubadora, de forma que essas empresas possam ter um melhor desempenho em seus negócios. Fornece serviços administrativos, administra todos os serviços terceirizados, gerencia o condomínio e faz o controle, acompanhamento/gerenciamento dos projetos. É responsável pela coordenação, supervisão e implementação do processo de certificação da qualidade.

Em seu modelo de gestão, a incubadora da PUC, inserida no ambiente do Instituto Gênesis, mostra-se bastante integrada às iniciativas/atividades da universidade. Estas se traduzem em objetivos como o de "ser reconhecida como um canal de prestação de serviços da universidade para a sociedade", o de "transferir conhecimentos da PUC/RJ para a sociedade", ou ainda, o objetivo de "difundir a cultura empreendedora dentro do ambiente universitário".

\section{Incubadora de base tecnológica da Coppe/UFRJ ${ }^{4}$}

A Fundação Coordenação de Projetos, Pesquisas e Estudos Tecnológicos (Coppetec) é uma instituição de direito privado, sem fins lucrativos. É vinculada por regimento e estatuto aos objetivos maiores da Coordenação dos Programas de Pós-graduação em Engenharia da Universidade Federal do Rio de Janeiro (Coppe/UFRJ) e se destina a viabilizar a prestação de serviços técnicos especializados aos diversos agentes públicos e privados do desenvolvimento nacional.

\section{A incubadora tecnológica da Coppe/UFRJ}

A incubadora de empresas da Coppe/UFRJ funciona na Cidade Universitária, na Ilha do Fundão, desde 1994. Tem uma localização privilegiada por estar instalada ao lado de importantes vias de acesso da cidade do Rio de Janeiro, como as linhas Amarela e Vermelha, a avenida Brasil e o aeroporto internacional Tom Jobim. Além disso, e de acordo com o próprio conceito de incubadora, as empresas se aproveitam da proximidade com os laboratórios e os centros de pesquisa instalados na Cidade Universitária.

\section{Fundamentos estratégicos da incubadora}

Missão: "apoiar o desenvolvimento tecnológico do país com a oferta de negócios provenientes de pesquisas e ser uma ferramenta voltada para o crescimento de emprego e renda".

\section{Objetivos estratégicos}

O projeto da incubadora tem como objetivo estratégico principal o apoio à formação de empresas de base tecnológica nas áreas de atuação de grupos de pesquisas da UFRJ.

\footnotetext{
${ }^{4}$ Coppe (2202); Coppetec (2002).
} 
Os candidatos selecionados podem utilizar as instalações e facilidades da incubadora por um prazo de três anos, prorrogável por mais dois períodos de um ano. A permanência na incubadora começa por um período probatório de seis meses. O processo de seleção de empresas começa com o lançamento de um edital, logo após a graduação de algumas empresas. O conselho da incubadora é quem avalia, critica e seleciona os projetos, mas sempre baseado nos mesmos critérios, que são:

- viabilidade técnica/econômica;

- perfil do grupo proponente;

- grau de inovação de tecnologia;

- impacto modernizador na economia e

- a possibilidade de interação da empresa com atividades de pesquisa desenvolvidas na universidade.

A proposta a ser apresentada pelos interessados deve compor um plano de negócios contendo informações técnicas, econômico-financeiras, mercadológicas e gerenciais do projeto, seguindo um roteiro preestabelecido e disponível aos interessados na gerência da incubadora.

A incubadora oferece uma infra-estrutura de equipamentos e serviços como: copiadora, fax, rede de computadores, acesso à Internet e serviços de limpeza e de segurança. Além dessa estrutura física, as empresas incubadas recebem assessoria e treinamento em:

- comercialização;

- assessoria de marketing;

- assessoria de finanças;

- assessoria jurídica - que orienta as empresas na elaboração de contratos e na negociação com parceiros e clientes; e

- assessoria de comunicação e imprensa.

Além disso, há um staff que assessora as empresas de forma integral e permanente.

\section{A gestão da incubadora:}

- função marketing - comunicar a existência e o trabalho da incubadora ao público-alvo (os alunos e professores da UFRJ), à sociedade, à liderança local (os coordenadores dos programas da Coppe/UFRJ), a empresas (multisetorial) e aos alunos de pós-graduação da Coppe/UFRJ;

- apoio jurídico - orientar e dar informações no campo do direito para a incubadora e para as empresas residentes;

- gestão financeira - atingir a auto-sustentação operacional, pois a incubadora não recebe financiamentos, mas sim aporte financeiro para investimentos e custeio operacional;

- acompanhamento dos indicadores:

a. da incubadora - pela equipe, com determinação de um responsável para cada item ou grupo de itens. A execução é orientada pelo cronograma, enquanto o acompanhamento e o controle são realizados empiricamente;

b. das empresas - não existe uma sistemática para acompanhamento dos indicadores, ao menos, dos financeiros;

- assessoria de comunicação - promover a imagem institucional da incubadora e das empresas residentes. Nesse sentido, a assessoria de comunicação funciona como um canal de diálogo entre a incubadora e o público; 
- assessoria financeira - ajudar a elaborar o planejamento financeiro das empresas residentes e dar apoio na análise de investimentos; e

- assessoria administrativa - apoiar as empresas residentes com recursos administrativos.

\section{Integração com a entidade gestora}

Em seu modelo de gestão, a incubadora da Coppe mostra-se integrada à entidade gestora. O incentivo à pesquisa que a incubadora tem como sua missão é resultado da forte ligação que esta tem com os estudos de pós-graduação em engenharia desenvolvidos pela Coppe.

\section{Conclusão}

Em vários momentos, a pesquisa evidenciou que houve uma adesão do modelo de gestão conceitual apresentado àqueles modelos identificados na amostra qualificada, como demonstram:

- a congruência entre os objetivos estratégicos das incubadoras e as diretrizes estabelecidas pelas instituições gestoras;

- a aplicação de ferramentas de planejamento estratégico para posicionar a incubadora em relação ao futuro; e

- o uso do processo de pré-incubação, com a necessidade da apresentação de um plano de negócios pelos candidatos ao programa de incubação, ressaltando a coerência com a realidade dos nossos empreendedores de pouca ou nenhuma preocupação em planejar o negócio desde seu nascimento.

No apoio induzido ou assistido às empresas residentes obteve-se, de forma inequívoca, uma prova de que não basta ter um dispositivo ou serviço tecnologicamente inovador, mas de que é necessário "pensar" estrategicamente o negócio. Contudo, deve ser salientado que há muito a ser feito em termos do uso de ferramentas de monitoramento e controle estratégico.

O movimento de melhoria gerencial das incubadoras de empresa é uma necessidade, e deve ser incrementado, na medida em que os recursos para financiamento das mesmas sejam disputados por um maior número de incubadoras. Atrelado a isso, há uma maior preocupação com a eficiência/eficácia dos recursos aplicados pelas instituições financiadoras.

Esses fatos, associados a outros aspectos como, por exemplo, as especificidades dos controladores, fazem com que as incubadoras invistam tanto no seu desenvolvimento gerencial quanto na capacitação dos empresários selecionados nos programas de incubação.

Cabe destacar um problema complexo detectado nas incubadoras estudadas e ressaltado por vários dos autores pesquisados: os múltiplos stakeholders e, particularmente, entre estes, os financiadores. Essa multiplicidade dificulta uma gestão considerada por todos como adequada aos seus interesses, os quais, por vezes, são contraditórios. 


\section{Referências}

ARANHA, J. A. S. et al. Modelo de gestão para incubadoras de empresas. Rio de Janeiro: Rede de Tecnologia do Rio de Janeiro, 2002.

BAÊTA, A. M. C. O desafio da criação: uma análise das incubadoras de base tecnológica. Rio de Janeiro: Vozes, 1999.

BEARSE, P. The evaluation of business incubation projects: a comprehensive manual. Ohio: National Business Incubation Association, 1993.

BELL, C. G.; MCNAMARA, J. E. High-tech ventures: the guide for entrepreneurial success. [S.I.]: Addison-Wesley Publishing Company, 1991.

CAULLIRAUX, H. M. Modelo de gestão para incubadora de empresas: uma estrutura de indicadores de desempenho. Rio de Janeiro: Rede de Incubadoras do Rio de Janeiro, 2001.

COPPE. Banco de dados. Disponível em: <http://www.coppe.ufrj.br>. Acesso em: 2002.

COPPETEC. Banco de dados. Disponível em: <http://coppetec.coppe.ufrj.br>. Acesso em: 2002.. Rio de Janeiro: Atlas, 1999. 